\title{
Review of topiramate for the treatment of epilepsy in elderly patients
}

\author{
This article was published in the following Dove Press journal: \\ Clinical Interventions in Aging \\ 8 April 2010 \\ Number of times this article has been viewed
}

\author{
BR Sommer' \\ HH Fenn ${ }^{2}$ \\ 'Department of Psychiatry, Stanford \\ University School of Medicine, \\ Stanford, California USA; ${ }^{2}$ Palo \\ Alto VA Healthcare System, Acute \\ Geropsychiatry Unit, Menlo Park \\ Division, Menlo Park, California, USA
}

Correspondence: BR Sommer Department of Psychiatry, 40I Quarry Road-2338, Stanford University School of Medicine, Stanford, California, USA 94305-5723

Tel + I 650-723-8567

$\mathrm{Fax}+\mathrm{I}$ 650-7253762

Email brsommer@stanford.edu
Abstract: Individuals over 65 years of age experience the new onset of seizures at a prevalence rate of roughly twice that of younger adults. Differences in physiology, need of concomitant medications, and liability for cognitive deficits in this population, make the choice of anticonvulsant drugs especially important. This paper reviews topiramate (TPM), a treatment for many types of seizures, with the above risks in mind. In particular, we discuss efficacy and pharmacokinetics with emphasis on the older patient, and adverse events in both the younger and older adult. With most studies of TPM-induced cognitive deficits having been performed in younger adults and volunteers, we discuss the implications for the older adult. Even in studies of younger individuals, up to 50\% discontinue TPM because of intolerable cognitive deficits. Most studies find specific declines in working memory and verbal fluency. In conclusion, we give recommendations for use of this antiepileptic drug in this population.

Keywords: topiramate, elderly, epilepsy, treatment, cognition, pharmacokinetics

\section{Introduction}

The literature on idiopathic symptomatic seizure disorders has consistently shown that the incidence increases with age, such that by the seventh decade, the risk doubles, and by the eighth, triples. ${ }^{1,2}$ Two separate population-based studies now have shown that at least $25 \%$ of patients with newly diagnosed unprovoked seizures are over 60 years old. ${ }^{3-5}$

The underlying etiologies may include cerebrovascular disease and stroke, occurring in up to half of cases. ${ }^{5-7}$ Interestingly, ictal activity may be found in small vessel disease, commonly seen on imaging in older individuals. ${ }^{8}$ After an obvious vascular event such as an acute, subarachnoid hemorrhage, a seizure may occur within hours. If seizures do occur in association with vascular disease, they are more likely to recur if dementia or another neurological disease co-exists. ${ }^{7}$ In evaluating the most common etiologies for unprovoked seizures, one prospective population-based study has found that the most common etiologies were stroke, followed by brain tumor, and Alzheimer's disease. ${ }^{3}$ If stroke had been the etiology, the location was important, with cortical involvement being more likely to produce seizure activity than sub-cortical location of the stroke. ${ }^{8}$

The clinical features of epilepsy in elderly patients often are quite different from those of younger patients, with studies showing that most often, older patients experience simple partial or complex partial seizures. ${ }^{7,9}$ Although the estimated annual incidence is as high as 134 per 100,000 in older individuals, some authors believe this to be a conservative number, with misdiagnosis and un-diagnosis common. 
Older patients often present with altered mental status, confusion, memory lapse, or syncope, ${ }^{2}$ making the seizure disorder go unrecognized. It has been shown that in older patients with a new diagnosis of epilepsy, the primary care physician or internist had made the correct diagnosis only $73.3 \%$ of the time. Other diagnoses may include altered mental status (41.8\%), confusion, $(37.5 \%)$, blackout spells (29.3\%), and memory disturbance $(17.2 \%)$ - the numbers do not add up because patients may have more than one diagnosis made. ${ }^{10}$ The most common type of seizure in the older adult is partial onset, occurring in $68 \%$, with $10 \%$ to $30 \%$ presenting as tonic-clonic status epilepticus. ${ }^{7}$

Older individuals, relatively frail due to their susceptibility to both cerebrovascular disease and to new onset seizure disorder, require that safe medications for seizure control be utilized to treat their disorders. The ideal medication for seizure control would have no drug-drug interactions, especially with antihypertensive drugs, limited sedation, low risk of gait disturbance, no effect on appetite, no associated metabolic disturbance, and no alteration of cognition. There are no medications presently available to fit this profile. However, compared to other anticonvulsants, the side effect profile of topiramate (TPM) may offer some patients an alternative under certain circumstances.

In this paper, we plan to discuss the use of TPM in older patients with both generalized and partial seizures. The focus in this paper is on efficacy studies, pharmacokinetics, drug interactions and side effects in the older population, especially as they apply to individuals with concurrent cognitive impairment due to medical co-morbidity. How TPM would compare to an ideal AED for use in the elderly is discussed.

\section{Mechanism of TPM}

The anticonvulsant activities of TPM differ from those of other anti-epileptic drugs (AEDs) such as phenytoin (PHT) and carbamazepine (CBZ). It does exhibit the property of state and voltage dependent blockade of neuronal $\mathrm{Na}^{+}$ channels, as do the others, but in addition, TPM influences the activity of $\mathrm{Ca}^{2+}, \mathrm{GABA}_{\mathrm{A}}$ receptors, and AMPA ( $\alpha$-amino-3hydroxy-5-methylisoxazole-4-propionic acid)/kainate glutamate receptors. ${ }^{11}$ TPM also has the unusual quality of inhibiting some isozymes of carbonic anhydrase. ${ }^{12}$ The ophthalmologic implications will be discussed in a separate section. ${ }^{13}$

\section{Efficacy studies of TPM in the elderly}

TPM has been reported to show effectiveness in most seizure types except perhaps for absence. ${ }^{9}$ Studies have found it useful for intractable epilepsy. ${ }^{14}$ However, few studies have been performed specifically on individuals over 65 .

Most efficacy studies of TPM as an AED have involved the population younger than 67 years old. ${ }^{14-23}$ Many efficacy studies of older individuals have included them only as part of general adult studies. ${ }^{24-26}$ Table 1 lists trials of TPM that have incorporated older patients.

For example, Gilliam and colleagues evaluated 24 individuals over 65 as part of an efficacy study of partial complex seizures; a total of 252 patients were evaluated. ${ }^{25}$ Arroyo assessed 10 patients over age 65 as part of a general study evaluating a total of 470 patients. ${ }^{26}$ An open label study by Stefan and colleagues exclusively evaluated an older cohort of 107 patients (mean age of 69 years) with TPM mono-therapy, for a one-year period. ${ }^{27} 48 \%$ of patients began TPM as monotherapy, (mean dose of TPM was $98 \pm 50 \mathrm{mg}$ /day) with the percentage increasing to $65 \%$ at endpoint. The mean TPM dose for those in combination therapy was $153 \pm 87 \mathrm{mg}$ /day. Mean monthly seizure frequency overall decreased from $3.7 \pm 15$ to $1.6 \pm 7.7$, with $78 \%$ of patients showing at least $50 \%$ seizure reduction, and $44 \%$ being seizure free for the one year period.

In summary, data shows lower doses of TPM, when used as monotherapy for the treatment of epilepsy in the older patient, may be effective, with 50 to $75 \mathrm{mg}$, sufficient for seizure control. ${ }^{28}$

\section{Pharmacokinetics Absorption}

TPM is rapidly and almost completely absorbed by the gut, reaching peak plasma concentrations between 2 and 4 hours after ingestion, ${ }^{29,30}$ and bioavailability after oral administration is almost entirely unchanged, between $81 \%$ and $95 \%{ }^{31}$ Factors that may slow the absorption include high fat foods and concomitant medications, such as valproate, carbamazepine, and phenytoin, which produce changes consistent with the metabolic changes resulting from cytochrome $\mathrm{P} 450$ enzyme induction. ${ }^{32,33}$

\section{Distribution and protein binding}

While plasma albumin levels decline with age, alpha 1 glycoprotein either remains unchanged or may increase. Albumin and alpha-1 acid glycoprotein (AAG) are responsible for most plasma drug binding. Albumin preferentially binds acidic drugs and AAG primarily binds alkaline or neutral drugs. Competition for protein binding may result in fewer available binding sites for albumin, and transient increases in free drug concentrations may occur, influencing the concentration and 
Table I Studies assessing the effects of TPM on epilepsy in older patients. The number is far fewer than in younger adults, and most often older subjects are included only as part of studies involving younger adults

\begin{tabular}{|c|c|c|c|c|c|c|}
\hline \multirow[t]{2}{*}{ Author } & \multirow[t]{2}{*}{ Seizure type } & \multicolumn{2}{|l|}{$\begin{array}{l}\text { Number of } \\
\text { subjects }\end{array}$} & \multirow{2}{*}{$\frac{\text { Min dose }}{(\mathrm{mg})}$} & \multirow{2}{*}{$\begin{array}{l}\text { Max dose } \\
(\mathrm{mg}) \\
\end{array}$} & \multirow[t]{2}{*}{$\%$ SF at end of study } \\
\hline & & Older adults & Total & & & \\
\hline Gilliam²5 & Partial epilepsy & $24(>65)$ & 252 & $\begin{array}{l}50, \text { or } 25 \\
\text { if } \leq 50 \mathrm{~kg}\end{array}$ & $\begin{array}{l}500, \text { or } 200 \text { if } \\
\leq 50 \mathrm{~kg}\end{array}$ & $\begin{array}{l}54 \% \text { on } 500 \mathrm{mg}, \\
39 \% \text { on } 200 \mathrm{mg}\end{array}$ \\
\hline Privitera $^{\mathrm{a}, 24}$ & Newly dx epilepsy & 37 & 409 & 100 & 200 & $49 \%$ \\
\hline Arroyo ${ }^{26}$ & Epilepsy & 10 & 470 & 50 & 400 & $\begin{array}{l}\text { After } 12 \mathrm{mos}: \\
76 \% \text { on } 400 \mathrm{mg}, \\
59 \% \text { on } 50 \mathrm{mg}\end{array}$ \\
\hline Groselj $^{89}$ & Epilepsy & $60(>60)$ & & 100 & 400 & $\begin{array}{l}64 \% \mathrm{SF} \\
87 \% \geq 50 \%\end{array}$ \\
\hline Guerrini ${ }^{90}$ & $\begin{array}{l}\text { Focal and generalized } \\
\text { epilepsy }\end{array}$ & $\begin{array}{l}\text { Mean age } 69.2 \text { ( } 1-88 \text { years } \\
\text { old), ages not further } \\
\text { described }\end{array}$ & & 25 & 500 & $\begin{array}{l}44.3 \% \mathrm{SF} \\
76.3 \% \geq 50 \%\end{array}$ \\
\hline Runge $^{91}$ & $\begin{array}{l}\text { Newly or recently } \\
\text { dx epilepsy }\end{array}$ & $145(\geq 65)$ & & 50 & 100 & $\begin{array}{l}40.7 \% \text {, mean } \\
\text { duration } 185 \text { days }\end{array}$ \\
\hline Stefan ${ }^{27}$ & Elderly, epilepsy & 107 (mean age 69) & & 98 (monotx) & $\begin{array}{l}153 \\
\text { (adjunctive tx) }\end{array}$ & $78 \% \geq 50 \%$ \\
\hline Ramsay ${ }^{92}$ & $\begin{array}{l}\text { Elderly, partial-onset } \\
\text { seizures }\end{array}$ & $77(>60)$ & & $50(N=38)$ & $200(N=39)$ & $\begin{array}{l}52 \% \text { on } 50 \mathrm{mg}, \\
58 \% \text { on } 200 \mathrm{mg}\end{array}$ \\
\hline
\end{tabular}

aStudy compared TPM with CBZ and VPA.

Abbreviations: $\mathrm{dx}$, diagnosis; SF, seizure free; tx, therapy; TPM, topiramate; CBZ, carbamazepine; VPA, valproate.

clearance of concomitantly administered medications. ${ }^{34,35}$ TPM binds to AAG, globulins, lipoproteins, and erythrocytes, only binding to plasma proteins to a small degree $(13 \%-17 \%) .{ }^{36,37}$ As a result of these binding and distribution properties, TPM free (unbound) serum concentrations may not be as affected as other medications by age-related reductions of plasma albumin levels, or by significant protein binding displacement interactions when used in combination with lipophilic and protein-bound AEDs. ${ }^{38}$

\section{Metabolism}

Around $70 \%$ of TPM is excreted without metabolism, unchanged in the urine, unless in the presence of other medications which are potent enzyme inducers. ${ }^{37,39}$ The six known metabolites of TPM themselves show little to no pharmacological activity. ${ }^{37}$ While TPM alone does not appear to either inhibit or induce drug metabolizing enzymes at clinical doses, it does inhibit CYP2C19 at plasma concentrations doses equivalent to $5 \%$ to $15 \%$ times higher than recommended. ${ }^{33}$ Regression analysis has found that when combined with PHT, CBZ, phenobarbital, and oxcarbazepine, TPM concentrations were significantly lower, compared with TPM concentrations during monotherapy. ${ }^{40}$ TPM alone has a half-life of around 24 hours, decreasing by about $50 \%$ in the presence of enzyme inducing medications. This results in a rise of metabolized TPM by
$50 \%$ to $70 \%{ }^{39}$ Neither valproate (VPA) nor lamotrigine (LTG) have a significant influence on TPM metabolism. ${ }^{39}$

Most AEDs are eliminated primarily by the clearance of unbound drug. Aging is associated with an increase in unbound drug, associated with a decrease in clearance. Without a commensurate decrease in protein binding, serum concentrations of a drug would be expected to rise. One single-dose study of 16 volunteers between ages 65 to 85 confirmed this by finding that TPM clearance was reduced by about $20 \%$ when compared to 16 younger adult controls. ${ }^{41}$ This study, however, seems to be at odds with another finding that while small increases in serum TPM concentrations have been recorded in patients with impairment in hepatic function, age-related changes in hepatic function alone do not appear to result in significant clinical impact or the need for adjustments in TPM dosing. ${ }^{27}$

As monotherapy, TPM has a half-life of around 24 hours, decreasing by about $50 \%$ in the presence of enzyme inducers, making the amount of metabolized TPM rise by $50 \%-70 \%{ }^{39}$

\section{Renal excretion}

TPM is primarily excreted unchanged by the kidneys, and is not extensively metabolized by the liver. ${ }^{42}$ Aging may decrease tubular excretory capacity and glomerular filtration rate by $25 \%$ to $50 \%$ by age $90 .{ }^{43}$ While renal elimination of most drugs 
is a measure of endogenous creatinine clearance, renal function and creatinine clearance are not always reliable measures in the elderly. Reduced muscle mass with ensuing decreased muscle breakdown results in a reduced entry of creatinine into the circulation. A normal serum creatinine, particularly in an older woman, may reflect incipient renal failure. ${ }^{43}$

One study compared a group of 65-85-year-olds with compromised renal function to younger adults, after a single oral $100 \mathrm{mg}$ dose of TPM. The TPM clearance was reduced in the elderly, with the half-life $13 \%$ longer than in the younger subjects. There also was a $23 \%$ higher maximum plasma concentration. ${ }^{41}$ Therefore, it is generally felt that the recommended dose of TPM, particularly in the older patient, whose clearance may decrease by up to $50 \%$, should be lower even in the face of a normal serum creatinine. ${ }^{44}$

\section{Adverse drug reactions}

An adverse drug reaction (ADR) is defined as "an appreciably harmful or unpleasant reaction, resulting from an intervention related to the use of a medicinal product, which predicts hazard from future administration and warrants prevention or specific treatment, or alteration of the dosage regimen, or withdrawal of the product". ${ }^{45}$

The study in the above section by $\operatorname{Stefan}^{27}$ found that during the TPM trial, $67 \%$ of the 75 patients that had been taking AEDs pre-trial, reported adverse events (AEs), and of those, $43 \%$ of the ADRs were considered likely due to the medication. In $5 \%$ of patients, convulsions leading to hospitalization were reported. Other ADRs included: dizziness, fatigue, headache, cognitive disturbance, depression, paresthesia, and nausea. In this study, 12\% of the patients reported cognitive disturbance; $11 \%$ described memory impairment, and 2 subjects had additional language impairment. Two subjects reported additional difficulties with praxis and psychomotor slowing. In all, however, TPM was considered well tolerated, with good efficacy. While there were cognitive complaints in a significant minority of patients, they seemed to be tolerable in most cases. ${ }^{27}$

In a study of the young adult population, ADRs in general were markedly attenuated by slowly titrating the dose. A multi-center study of 213 patients aged 16 to 65 (mean age $30.1 \pm 10.2$ ), with intractable epilepsy (defined as $>2$ seizures in a 4 week period), found that by beginning TPM at $25 \mathrm{mg}$ increasing by $25 \mathrm{mg}$ per week, doses of $300 \mathrm{mg}$ per day could be reached, and both efficacy and AEs were comparable to the authors' previous trial using $600 \mathrm{mg}$. During the study, 22\% developed ADRs entering the titration phase, $81 \%$ during the titration phase, and $45 \%$ during the maintenance phase of the study. The most common AE was dizziness (10\%). Other ADRs were somnolence (3.3\%), anorexia (2.3\%), and weight loss $(2.3 \%)$, with other ADRs reported at less than $2 \%$. The mean weight loss was $1.1 \pm 1.3 \mathrm{~kg} .{ }^{46}$ An earlier study had examined the incidence of all ADRs in patients who had taken TPM prior to that date, assessing studies until 1996. While the ages of the patients were not given, the authors found that of the 1809 individuals originally exposed to TPM for the treatment of partial seizures, the percentage of subjects with confusion, abnormal thinking or impaired concentration were as follows: $8 \%$ on placebo, $40 \%$ on $200 \mathrm{mg}, 36 \%$ on $400 \mathrm{mg}$ $59 \%$ on $600 \mathrm{mg}, 58 \%$ on $800 \mathrm{mg}$ and $75 \%$ on $1000 \mathrm{mg}$. ADRs were considered mild to moderate in this population, whose age was not defined. ${ }^{47}$

One post marketing study of a mostly young adult population, (ages $18-60$, with $3 \%$ of the 701 patients older than 60) treated mostly for complex partial seizures, found that even this young cohort suffered from significant cognitive changes. In this open, observational study, only $2.4 \%$ of the patients were taking TPM as monotherapy, suggesting that the ADRs were possibly a result of not only combination therapy, but of the concomitant neuropsychiatric diagnoses that the authors mention that were also present in the population studied. Psychomotor slowing was found in $47.8 \%$ of patients, cognitive ADRs not otherwise specified in $39.1 \%$, and behavioral changes were found in 3 patients (18\%). In subjects without co-morbid psychiatric diagnoses, psychomotor slowing occurred in only $29.9 \%$ of patients. No seizure type put patients at increased risk for discontinuing TPM; CBZ seemed to be the concomitant medication most often associated with discontinuation. Psychomotor slowing was the most consistent AE after 6 months. ${ }^{48}$

Another study of mostly young adults (mean age $32 \pm 16.8$ years old, oldest subject 75 ) found levetiracetam had a higher retention rate for patients than TPM; the most important reason given for discontinuation of TPM was cognitive side effects. ${ }^{49}$ The efficacy of the two medications was comparable. The specific cognitive effects of TPM in both volunteers and patients with epilepsy are discussed further below.

\section{Metabolic acidosis, nephrolithiasis, and osteopenia}

As a carbonic anhydrase inhibitor, TPM reduces the excretion of urinary citrate, resulting in a rise in urinary $\mathrm{pH}$. TPM has been found to inhibit the activity of specific carbonic anhydrase enzymes in the kidney, contributing to the development of metabolic acidosis, hypocitraturia, hypercalciuria and elevated urinary $\mathrm{pH}$-all of which 
may lead to an increased risk of nephrolithiasis. ${ }^{50,51}$ Other contributors to these calcium phosphate kidney stones include TPM-induced systemic metabolic acidosis and lower urinary citrate excretion. ${ }^{51}$ The hyperchloremic, non-anion gap metabolic acidosis may begin as early as 1 week after beginning TPM treatment or within 1 week of a dose increase. The calculi may develop in approximately $1.5 \%$ of patients on TPM, 2 to 4 times the incidence expected in the general population. ${ }^{52}$ The risk of nephrolithiasis is increased by pre-existing renal disease, respiratory disorders, diarrhea, status epilepticus and treatment with other carbonic anhydrase inhibitors, such as acetazolamide. To aid in its prevention, ample hydration is important when prescribing TPM. Metabolic acidosis may result in cardiac arrhythmia, osteomalacia, and osteoporosis, with an increase in risk of spontaneous bone fracture. While the clinician may prescribe alkaline products, the discontinuation or tapering of TPM may need to be considered. Monitoring of serum electrolytes every 6 months should be considered. ${ }^{52}$

\section{Weight loss}

Appetite suppression and weight loss have been documented in patients treated with TPM for both epilepsy and psychiatric disorders. In a recent 1-year, open-label, flexible-dose clinical trial of 107 elderly patients (mean age 69 years) on TPM, $4.7 \%$ noted a decreased appetite and $3.7 \%$ were found to have frank weight loss. Nausea was reported in $5.6 \%$ of the sample, leading to discontinuation of TPM in $1.9 \%$ of the study population. Body weight decreased by $1.8 \pm 4.6 \mathrm{~kg}$ from baseline to the follow-up visit six (6 months later), and decreased $1.9 \pm 5.0 \mathrm{~kg}$ from baseline to the visit 52 weeks later. Although desirable in overweight or obese patients, this effect may be unwanted in frail elderly or underweight patients. ${ }^{27}$

\section{Paresthesias}

In an analysis of tolerability of TPM for migraine prevention, paresthesias were found to be the most common among all ADRs: $35 \%$ of patients $(\mathrm{N}=2350$ taking $50 \mathrm{mg} /$ day complained of paresthesias, $51 \%$ on TPM $100 \mathrm{mg} /$ day $(\mathrm{N}=386), 49 \%(\mathrm{~N}=514)$ taking TPM of $200 \mathrm{mg} / \mathrm{day}$, and only $6 \%(\mathrm{~N}=445)$ on placebo. $8 \%$ of 386 subjects withdrew from the because of this complaint. ${ }^{53}$

\section{Secondary angle closure glaucoma and decreased vision}

While rare, TPM has been associated with the unusual AE of acute, secondary angle closure glaucoma. This ophthalmologic emergency, usually treated with the carbonic anhydrase inhibitor acetazolamide, cannot successfully be treated in this standard manner in the presence of TPM, also with these properties. ${ }^{12}$ The sudden onset of decreased visual acuity accompanied by hyperemia and ocular pain has been reported, usually within the first month of treatment with TPM. This sudden adverse effect has been aborted with discontinuation of TPM. ${ }^{54-56}$

A case of a patient with sudden decreased vision while on TPM also has been described. Ophthalmologic exam showed findings consistent with maculopathy, but the patient's vision did not improve even after TPM had been discontinued for six months. ${ }^{13}$

\section{Psychiatric adverse events and TPM in the older adult}

Patients with epilepsy are reported to have 5 times the suicide rate as the general population, and patients with temporal lobe epilepsy (TLE) and complex partial seizures in particular have around a 25 -fold increase in rate. The psychological distress of seizure disorders, along with disturbances in serotonin metabolism contributing to the pathogenesis of suicidal behavior, may both be factors underlying these statistics. ${ }^{57}$ The mechanism of action of a particular AED prescribed is therefore critical, and recently, a number of AEDs have been associated with an increase in suicide risk in patients with both psychiatric and seizure disorders. ${ }^{57,58}$

In 2008, the US Food and Drug Administration (FDA) posted an advisory to healthcare professionals regarding suicidality associated with AEDs, stating that as a class, there is a possible risk between 11 such drugs, including TPM, and suicidal ideation, within 1 week of beginning treatment. This seems to occur to the same extent in both epilepsy and psychiatric patients. The FDA states that the risk is roughly twice that of placebo-treated patients $(0.43 \%$ versus $0.22 \%){ }^{59}$

Despite at least one significant study showing a positive effect on anger and depression in a young adult depressed population, ${ }^{60} \mathrm{TPM}$ has no effect on serotonin function, and would not be expected to exert an antidepressant effect on patients. In fact, overall, TPM-treated patients have a prevalence of suicidal ideation, attempts, and completed suicide of $0.5 \%$, compared with $0.15 \%$ of placebo recipients, in randomized, double-blind clinical trials. ${ }^{36}$ One author has recommended that until more studies have been completed, TPM not be used in patients with either TLE or hippocampal sclerosis, to prevent the onset of suicidal behavior. ${ }^{57}$

Other psychiatric adverse effects have been associated with TPM, and patients at increased risk may be those with the following characteristics: low seizure frequency prior to 
initiation of therapy, family and personal history of psychiatric disorder or epilepsy, personal history of febrile convulsions, presence of tonic/clonic seizures, and high starting dose or rapid titration of the medication. ${ }^{61}$ Specific reported psychiatric symptoms have included nervousness, depression, anorexia, agitation, and mood disruption. ${ }^{57}$ Psychiatric adverse effects have been seen as dose related, and one author has recommended initiating treatment in low doses, 15 to $25 \mathrm{mg} /$ day, with gradual titration to avoid these effects. ${ }^{37}$

In one observational follow-up study of 431 patients treated with TPM, psychiatric adverse events occurred in $103(23.9 \%)$ subjects. Specific events included 46 (10.7\%) with affective disorder, 16 (3.7\%) with psychotic disorder, and $24(5.6 \%)$ with aggressive behavior with or without irritability. Agitation, anxiety, and hostility were found in 17 (3.9\%). It was noted that the titration schedule of TPM appeared to be correlated with the onset of these psychiatric symptoms ${ }^{61}$ Mood instability, correlating with dose of TPM, has also been documented in $17 \%$ of patients in placebocontrolled studies, ${ }^{58}$ along with psychotic symptoms, which resolved upon discontinuation of TPM. ${ }^{62}$

\section{Concomitant medications and risk for delirium in the elderly}

Delirium, with its connotation of a grave prognosis, is often under-recognized in emergency departments. ${ }^{63}$ AEs due to TPM, however, do not appear to play a major role in its etiology. In a study of elderly patients with delirium, only $6 \%$ were found to be taking anticonvulsant medications. ${ }^{64}$ Common medication-induced causes of delirium include anticholinergic drugs ${ }^{65}$ and polypharmacy, as noted in a recent study finding that older patients with dementia and delirium had been taking more than 8 medications per day. ${ }^{64}$ Other medications frequently found to cause delirium include opiates, corticosteroids, and benzodiazepines. ${ }^{66}$

\section{Cognitive impairment in older patients with epilepsy}

Patients with epilepsy may suffer from cognitive impairment, multi-factorial in nature, independent of AEDs. Moreover, epilepsy may cause individuals to suffer from poorer education and fewer social supports than the general population, factors that have been seen in observational studies to be associated with an increased risk for cognitive decline in later years. ${ }^{67-70}$

Seizure disorders of differing etiologies have differing effects on cognition. For example, seizures that occur in conjunction with small strokes, depending on location, may have no demonstrable cognitive sequelae. But a seizure disorder resulting from a frontal lobe or limbic lesion may produce memory or language changes ${ }^{67}$ Idiopathic epilepsies are apparently less likely to be associated with cognitive impairment than seizure disorders secondary to localized lesions. ${ }^{67}$ TLE often is associated with deficits in language, verbal and visual skills, as discussed in studies below. Table 2 shows some of the studies assessing changes in cognition that have been performed on patients, both younger and older, with epilepsy.

But several studies attempting to assess cognition in patients with epilepsy have had methodological difficulties. One cross-sectional study evaluated 209 consecutive patients with TLE, monitoring the frequency of seizures per month, age of the patients at the onset of seizures, education, type of seizures, frequency of interictal epileptiform discharges, and AED taken. Factoring out these variables, the authors found that subjects with a longer duration of refractory TLE were the most impaired. The conclusion was that refractory TLE is associated with slow, ongoing cognitive decline. ${ }^{71}$ This correlational study, however, does not connote risk.

\section{TPM effects on cognition}

Many studies have compared the cognitive effects of TPM versus other AEDs in patients with partial epilepsy. These outcome studies have examined mostly young adults, with only a few studies exclusively involving the elderly. While the studies often have used differing neuropsychological batteries, when taken as a whole, the conclusions are similar - that there is such a marked effect on cognition that patients ask for discontinuation up to $47 \%$ to $50 \%$ of the time. ${ }^{72-74}$ Most of the studies have found deficits in working memory, and verbal fluency. ${ }^{74-77}$

One gross effect of TPM on daily life has been evaluated by examining motor vehicle performance and at least two studies have found TPM-related decreases in driving ability. ${ }^{72,78}$ In one, a subsample of patients with partial seizures taking part in a randomized, double-blind, controlled study comparing the cognitive effects of TPM and LTG, was administered a computerized task measuring scanning, divided attention, and effective field of view (via the Performance On-Line, or POL). ${ }^{72}$ The POL is thought to be an index for driving ability. Patients with a mean age of 40.2 (19-68), 3/4 of whom were under 50 years old, were administered mean doses of either TPM 298.0 (SD 8.6) $\mathrm{mg}$ or LTG 491.4 (SD 43.8) $\mathrm{mg}$ as adjuvant therapies to either PHT or CBZ for treatment of partial seizures. The TPM treated group suffered from restricted field of view after eight weeks, unable to overcome the deficits over the 
Table 2 Effects of epilepsy on cognition in young adults and the elderly

\begin{tabular}{|c|c|c|c|c|c|}
\hline Study & $\mathbf{N}$ & Age at testing & Epilepsy type & Cognitive tests & Results \\
\hline Jokeit ${ }^{71}$ & 209 & $\begin{array}{l}\text { Mean } \\
25.4-43.8\end{array}$ & TLE & $\begin{array}{l}\text { Full scale IQ } \\
\text { (est from subtests: } \\
\text { information, } \\
\text { comprehension, similarities, } \\
\text { digit symbol, picture } \\
\text { completion block design) }\end{array}$ & $\begin{array}{l}\text { Pts with }>30 \text { years of TLE } \\
\text { did worse than pts with } \\
\text { I5-30 years of TLE } \\
\text { Variables were controlled } \\
\text { (age of onset, education } \\
\text { polypharmacy) }\end{array}$ \\
\hline Martin $^{93}$ & 52 & $64.6 \pm 3.9$ & $\begin{array}{l}\text { Chronic } \\
\text { partial-intractable }\end{array}$ & $\begin{array}{l}\text { Mattis Dementia Rating Scale } \\
\text { (subtests: attention, } \\
\text { initiation, construction, } \\
\text { conceptualization memory, } \\
\text { logical memory, } \\
\text { immed and delayed recall, } \\
\text { word fluency) }\end{array}$ & $\begin{array}{l}\text { Impairments in all domains. } \\
\text { Those taking AED } \\
\text { poly-therapy } \mathrm{N}=1 \mathrm{I} \text { did } \\
\text { worse than those on } \\
\text { monotherapy attn, } \\
\text { initiation and memory, } \\
\text { and logical memory and } \\
\text { delayed recall }\end{array}$ \\
\hline Griffith $^{94}$ & $\begin{array}{l}78 \text { ( } 26 \text { with } \\
\text { epilepsy, } 26 \text { with } \\
\mathrm{MCl} ; 26 \text { controls) }\end{array}$ & $\begin{array}{l}64.7 \pm 3.8 \\
\text { in the epilepsy group }\end{array}$ & $\begin{array}{l}\text { Partial } \\
\text { complex epilepsy }\end{array}$ & $\begin{array}{l}\text { Weschler Memory Scale III } \\
\text { subtests: } \\
\text { Logical memory, } \\
\text { CFL Word fluency test } \\
\text { attention, memory } \\
\text { construction, initiation } \\
\text { conceptualization, } \\
\text { phonemic word fluency }\end{array}$ & $\begin{array}{l}\text { Patients with epilepsy on } \\
\text { AED poly-therapy had the } \\
\text { most cognitive deficits. } \\
\text { Those on monotherapy } \\
\text { were similar to the } \mathrm{MCl} \\
\text { patients not on } \\
\text { cholinesterase inhibitors }\end{array}$ \\
\hline
\end{tabular}

Abbreviations: AED, anti-epileptic drugs; attn, attention; est, estimate; immed, immediate; $\mathrm{MCl}$, mild cognitive impairment; pts, patients; TLE, temporal lobe epilepsy.

16 weeks of the study. This was not thought to be due to angle closure glaucoma, a rare adverse event of the medication. There were also deficits in simple target identification and divided attention performance, in comparison with the LTG treated group. This effect was similar to the effects of a low dose of alcohol $(0.045 \mathrm{mg} / \mathrm{dL})$ or a low dose of alprazolam $(0.5 \mathrm{mg})$.

Another study evaluating deaths in Washington State in which TPM had been detected in the serum by the medical examiner, discussed 3 cases in which TPM was thought to play a significant role, and several others in which it may have played a minor role. ${ }^{78}$

One interesting study evaluated cognitive function in patients with intractable partial seizures after discontinuation of TPM, finding that compared to controls undergoing discontinuation of another AED, all as a part of their presurgical preparation, there was a dramatic amelioration five of six measures of frontal lobe function (save for digits forward, improvements were seen in verbal fluency, digit span, trailmaking parts $\mathrm{A}$ and $\mathrm{B}$, and block tapping). These tests demonstrate improvement in verbal fluency and working memory ${ }^{79}$ The same author then retrospectively studied TPM versus LTG treated inpatients with pharmacoresistance, finding that the TPM treated patients scored more poorly on 20 of 23 neuropsychological tests. Specifically, not only were there significant decreases in verbal fluency and working memory, but also spatial processing, and tasks which require mental manipulation of material presented to the subject. The domains of cognition that were spared included visual processing speed and episodic verbal and nonverbal memory. ${ }^{76}$

In addressing whether low dose TPM affects cognition as adversely as does a higher dose, Lee et al compared the effects of 50,75, and $100 \mathrm{mg}$ on the cognition of 47 epilepsy patients, of a mean age of 31.4 (15-63). Sixteen patients (44\%) complained of intellectual difficulties after 1 year, and these dose-related deficits were noted in domains of short-term memory and word retrieval, even on the lowest dose. ${ }^{77}$

There may be one circumstance in which TPM is actually preferable to LTG. Werz et al found that $70 \%$ of normal volunteers taking either TPM or LTG after a 12-week trial, each at a maximum dose of $300 \mathrm{mg} /$ day, again preferred LTG, having performed better on 19 of 23 cognitive tests including (attention, memory, language, and cognitive and motor speed). Interestingly, $16 \%$ of patients preferred TPM, and $14 \%$ had no preference, not correlating with cognition or change in weight, but rather correlating with the mood state exam score (Profile of Mood States) ${ }^{80}$ While TPM is generally not used as a first line medication in the treatment of psychiatric disorders, there are occasional reports of its benefits in the treatment 

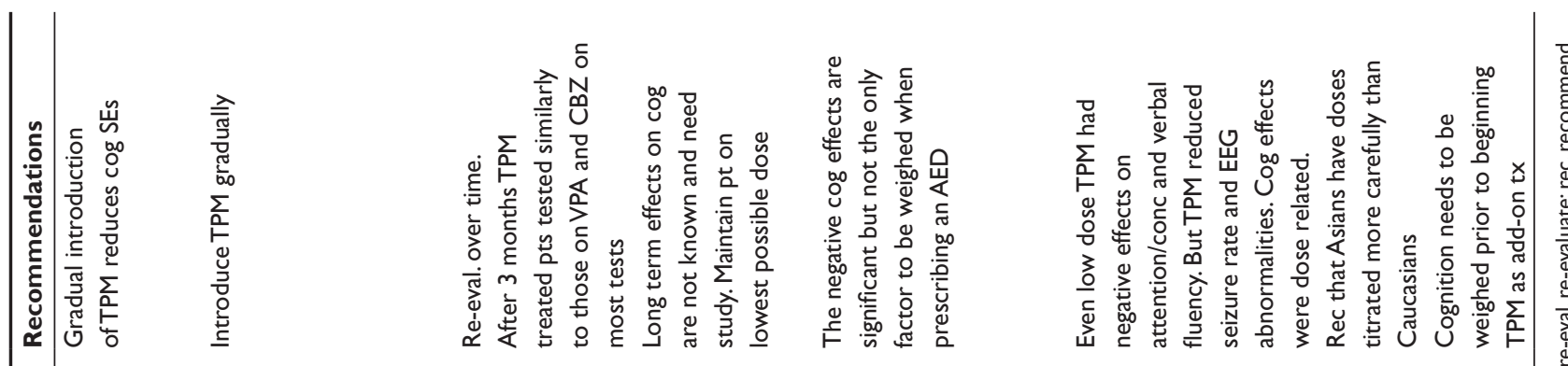

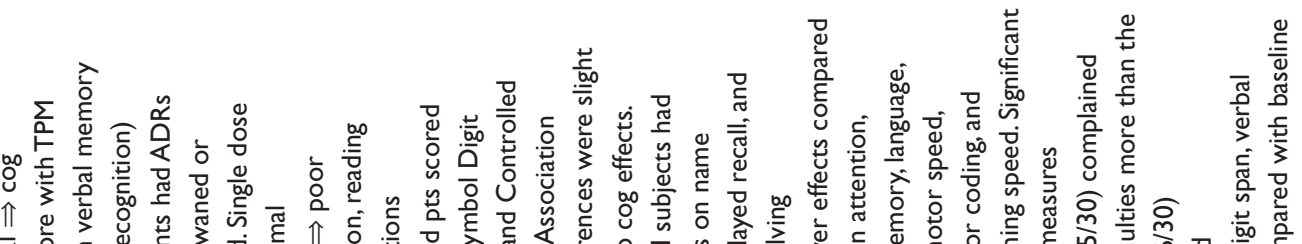

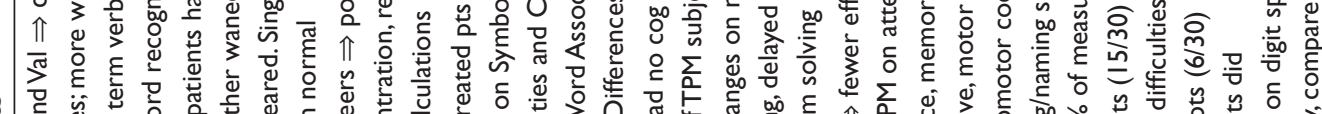

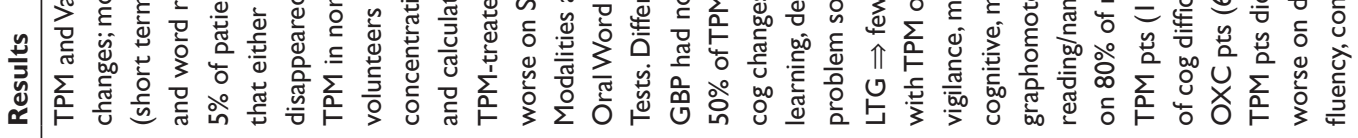

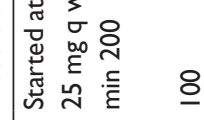

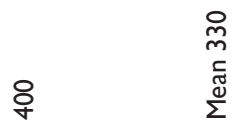

$\underset{\substack{m \\ m}}{\stackrel{\Xi}{\Perp}}$

임

오ํ

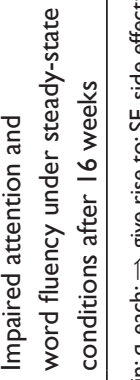

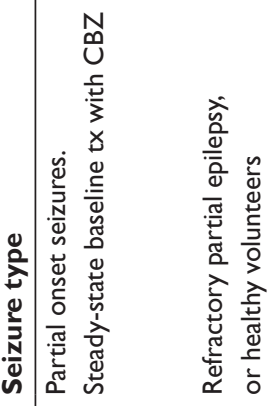

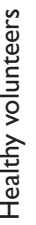

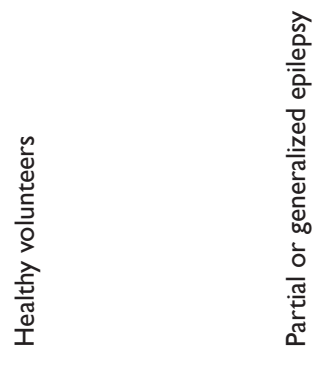

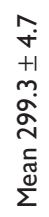

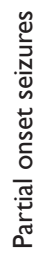

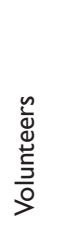

ํㅗㅇ t.

年

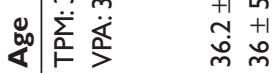

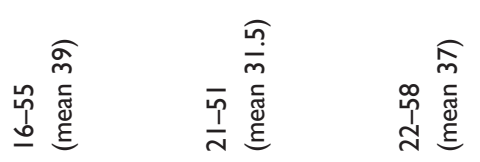

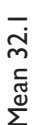

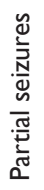

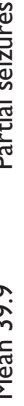

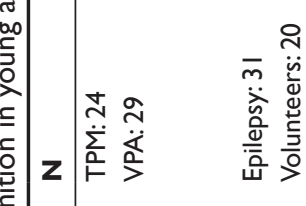

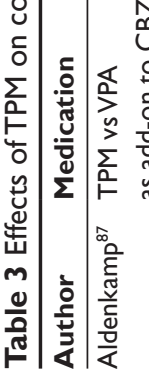

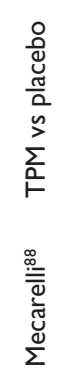

ชู

운

으

존

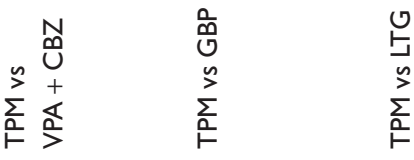

Oें

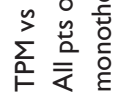

$\frac{\text { nू }}{\text { के }}$

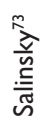

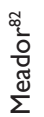

$\stackrel{ \pm}{\stackrel{ \pm}{\underline{z}}}$

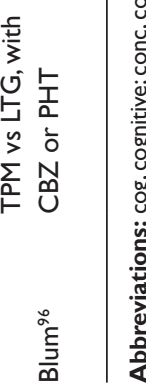


of the irritability associated with depression and some bipolar disorders. ${ }^{81}$

The above section notes that partial complex seizures present most often in older patients and often cause cognitive impairment. Furthermore, the older adult population in general is more vulnerable to intellectual slowing, memory, tracking, and concept formation than the younger adult patient, on whom most studies of cognition have been done. The fact that older individuals in general have a diminished cognitive reserve when compared with younger adults, and often take many medications, making them more delirium-prone leads to the speculation that TPM may be even less well-tolerated by this population. It is striking that assessments of TPM on cognition have included so few older adults, as Table 3 demonstrates.

The recommendations of the authors of these studies was to begin TPM slowly, maintain the patient at the lowest possible dose, below $200 \mathrm{mg}$ if possible, and to monitor the patient for amelioration of cognition over several months. In most of these studies, the overwhelming complaint was somnolence, causing even more distress than the cognitive slowing. This may have contributed to the inability to perform some of the required testing.

\section{Conclusions}

In comparing TPM to other available AEDs, two questions arise: 1 . How does this medication fare in terms of primary and adverse effects compared with the others, and 2. Is there available data on adverse events specifically in older adults.

TPM is an effective AED, which also has analgesic properties for migraine headache, not discussed in this article. In patients without dementia, and with obesity, it may have unique value, when compared with other AEDs that may cause weight gain. These virtues must be weighed against a body of evidence from the young adult literature on the cognitive adverse events. While somnolence may have played some minor role in test performance, most studies have found frank deficits in word and name recognition, memory, concentration, and speed ${ }^{82}$ These were subjectively noted by both patients and volunteers, and were a significant reason for withdrawal from studies. When compared with other AEDs such as LTG, levetiracetam, and oxcarbazepine, the findings were significant.

Few studies have investigated the effects of TPM in older patients in particular, by evaluating cognition, balance, somnolence, electrolyte balance, or weight loss. One recent review has found that among AEDs, the "worst offenders" included primidone, phenobarbital, and $\mathrm{PHT} .{ }^{83}$ Although TPM has not been evaluated in this population for these adverse effects, older patients are particularly susceptible to both cognitive impairment and risk of falling. This suggests that TPM, even in modest doses would very rarely be a first line AED.

The polypharmacy often prescribed to older adults, raises the risk of changes in TPM serum concentration. For example, clearance may be reduced by the following medications: amitriptyline, propranolol, lithium, and sumatriptan, all of which may increase the TPM level. VPA may lower the TPM level by $10 \%$ to $15 \%$. These facts have raised the question of the need for assessment of serum concentrations, to ensure not only medication adherence in this population, but to monitor serum fluctuations. The reported effective blood levels are from 5 to $20 \mathrm{mg} / \mathrm{L}$, but lower levels have been advocated to improve cognitive effects. ${ }^{84}$

TPM has many advantages, including posing no risk of hyponatremia - as does CBZ and oxcarbazepine - and the additional therapeutic values mentioned above. However, in the case of the older patient, preferable AEDs may include CBZ, GBP, LTG, and levetiracetam. ${ }^{85,86}$ TPM is not generally recommended as a first line treatment for epilepsy in the older patient, ${ }^{85}$ but when it is being considered, for the cognitively intact older individual, it is recommended that the dose begin at around $25 \mathrm{mg}$, increasing no more rapidly than by $25 \mathrm{mg}$ per week. The best results will be achieved by prescribing a total daily dose that results in low to moderate, rather than high serum levels. ${ }^{84,87,88}$

\section{Acknowledgments}

The authors gratefully acknowledge Philip Wasserstein MD, who reviewed the manuscript.

\section{Disclosures}

The authors declare no conflicts of interest.

\section{References}

1. Olafsson E, Hauser WA, Ludvigsson P, et al. Incidence of epilepsy in rural Iceland: a population-based study. Epilepsia. 1996;37:951-955.

2. Ramsay RE, Rowan JA, Pryor FM. Special considerations in treating the elderly patient with epilepsy. Neurology. 2004;62:S24-S29.

3. Forsgren L, Bucht G, Eriksson, et al. Incidence and clinical characterization of unprovoked seizures in adults: a prospective population-based study. Epilepsia. 1996;37:224-229.

4. Pohlmann-Eden B. Issues when treating epilepsy. Acta Neurol Scand. 2005;112(Suppl 181):40-46.

5. Hauser WA, Annegers JF, Kurland LT. Incidence of epilepsy and unprovoked seizures in Rochester, Minnesota: 1935-1984. Epilepsia. 1993;34:453-468.

6. LaRoche SM, Helmers SL. Epilepsy in the elderly. The Neurologist 2003;9:241-249

7. Stephen LJ, Brodie MJ. Epilepsy in elderly people. Lancet. 2000;355:1441-1446.

8. Lambrakis CC, Lancman ME. The phenomenology of seizures and epilepsy after stroke. J Epilepsy. 1998;11:233-240.

9. Faught E. Epidemiology and drug treatment of epilepsy in elderly people. Drugs Aging. 1999;15:255-269. 
10. Ramsey RE. Challenges in the diagnosis and treatment of the elderly patient with epilepsy. Annual Meeting of the Southern Clinical Neurological Society, January 20, 2003; Ixtapa, Mexico.

11. Shank RP, Gardocki JF, Streeter AJ, et al. An overview of the preclinical aspects of topiramate: Pharmacology, pharmacokinetics, and mechanism of action. Epilepsia. 2000;41(Suppl 1):S3-S9.

12. Dodgson SJ, Shank RP, Maryanoff BE, et al. Topiramate as an inhibitor of carbonic anhydrase isoenzymes. Epilepsia. 2000;41(Suppl 1):S35-S39.

13. Peyenburg S, Weyland C, Reuber M. Presumed topiramate-induced maculopathy. Epilepsy Behavior. 2009 Jan 14. [Epub ahead of publication].

14. Faught E, Wilder BJ, Ramsay RE, et al. Topiramate placebo-controlled dose-ranging trial in refractory partial epilepsy using 200-, 400-, and 600-mg daily dosages. Neurology. 1996;46:1684-1690.

15. Korean Topiramate Study Group. Topiramate in medically intractable partial epilepsies: double-blind placebo-controlled randomized parallel group trial. Epilepsia. 1999;40:1167-1774.

16. Sharief M, Viteri C, Ben-Menachem E, et al. Double-blind, placebo-controlled study of topiramate in patients with refractory partial epilepsy. Epilepsy Research. 1996;25:217-224.

17. Tassinari CA, Michelucci R, Chauvel P, et al. Double-blind, placebo-controlled trial of topiramate ( $600 \mathrm{mg}$ daily) for the treatment of refractorypartial epilepsy. Epilepsia. 1996;37:763-768.

18. Ben-Menachem E, Henriksen O, Dam M, et al. Double-blind, placebo-controlled trial of topiramate as add-on therapy in patients with refractory partial seizures. Epilepsia. 1996;37:539-543.

19. Privitera M, Fincham R, Penry J, et al. Topiramate placebo-controlled dose-ranging trial in-refractory partial epilepsy using 600-, 800-, and 1,000-mg daily dosages. Neurology. 1996;46:1678-1683.

20. Marson AG, Al-Kharusi AM, Alwaidh M, et al. The SANAD study of effectiveness of valproate, lamotrigine, or topiramate for generalised and unclassifiable epilepsy: an unblinded randomised controlled trial. Lancet. 2007;369:1016-1026.

21. Sachedeo RC, Reife RA, Lim P, et al. Topiramate monotherapy for partial onset seizures. Epilepsia. 1997;38:294-300.

22. Reife R, Pledger G, Wu SC. Topiramate as add-on therapy: Pooled analysis of randomized controlled trials in adults. Epilepsia. 2000;41(Supp1 1):66-71.

23. Montouris GD, Biton V, Rosenfeld WE. Nonfocal generalized tonic-clonic seizures: response during long-term topiramate treatment. Topiramate YTC/YTCE Study Group. Epilepsia. 2000;41(Suppl 1):77-81.

24. Privitera MD, Brodie MJ, Mattson RH, et al. Topiramate, carbamazepine and valproate monotherapy: double-blind comparison in newly diagnosed epilepsy. Acta Neurol Scand. 2003;107:165-175.

25. Gilliam FG, Veloso F, Bobhof MAM, et al. A dose-comparison trial of topiramate as monotherapy in recently diagnosed partial epilepsy. Neurology. 2003;60:196-202.

26. Arroyo S, Dodson WE, Privitera MD, et al. Randomized dose-controlled study of topiramate as first-line therapy in epilepsy. Acta Neurol Scand. 2005;112:214-222.

27. Stefan H, Hubbertz L, Peglau I, et al. Epilepsy outcomes in elderly treated with topiramate. Acta Neurol Scand. 2008;118:164-174.

28. Kurth C, Gaida-Hmmernick B, Hagemann C. Impact of low-dose topiramate monotherapy for epilepsy in adults with focal and generalized seizures. [abstract only, full paper in German]. Aktuelle Neurologie. 2007;34:276-282.

29. Rosenfeld WE. Topiramate: a review of preclinical, pharmacokinetic, and clinical data. Clin Therapeutics. 1997;19:1294-1308.

30. Langry HD, Gillis JC, Davis R. Topiramate; a review of its pharmacodynamic and pharmacokinetic properties and clinical efficacy in the management of epilepsy. Drugs. 1997;54:752-773.

31. Johannessen SI, Tomson T. Pharmacokinetic variability of newer antiepileptic drugs: When is monitoring needed? Clin Pharmacokinet. 2006;45:1061-1075.

32. Doose DR, Walker SA, Gisclon LG, et al. Single-dose pharmacokinetics and effect of food on the bioavailability of topiramate, a novel antiepileptic drug. J Clin Pharmacol. 1996;36:884-891.
33. Sachdeo RC, Sachdeo SK, Levy RH, et al. Topiramate and phenytoin pharmacokinetics during repetitive monotherapy and combination therapy to epileptic patients. Epilepsia. 2002;43(7):691-696.

34. Roberts J, Turner N. Pharmacodynamic basis for altered drug action in the elderly. Clin Geriatr Med. 1988;4:127-149.

35. Gidal BE. Topiramate. In: Mattson RH, Meldrum BS, Perucca Levy RH, editors. Antiepileptic Drugs, 5th Edition. New York: Lippincott Williams Wilkins/Wolters Kluwer Company; 2002. p. 735-739.

36. Janssen-Cilag Ltd.: High Wycombe, UK: Janssen-Cilag Ltd., TOPO$\mathrm{MAX}^{\circledR} 25 \mathrm{mg}, 50 \mathrm{mg}, 100 \mathrm{mg}, 200 \mathrm{mg}$ tablets and sprinkle capsule 15 , 25 , or $30 \mathrm{mg}$ : summary of product characteristics. November 2006.

37. Shank RP, Maryanoff BE. Molecular pharmacodynamics, clinical therapeutics, and pharmacokinetics of topiramate. CNS Neurosci Ther. 2008; $14: 120$.

38. Bialer M, Doose DR, Murthy B, et al. Pharmacokinetic Interactions of Topiramate. Clin Pharmacokinet. 2004;43:763-780.

39. Britzi M, Perucca E, Soback S, et al. Pharmacokinetic and metabolic investigation of topiramate disposition in healthy subjects in the absence and in the presence of enzyme induction by carbamazepine. Epilepsia. 2005;46:378-384.

40. Patsalos PN, Froscher W, Pisani F, van Rijn CM. The Importance of drug interactions in epilepsy therapy. Epilepsia. 2002;43:365-385.

41. Doose DR, Larsson KL, Natarajan J, et al. Comparative single-dose pharmacokinetics of topiramate in elderly versus young men and women. Epilepsia. 1998;39(Suppl 6):56.

42. Perucca E, Birnbaum A, Cloyd JC, et al. Pharmacological and clinical aspects of antiepileptic drug use in the elderly. Epilepsy Res. 2006;68(Suppl 1):849-863.

43. Turnheim K. When drug therapy gets old: pharmacokinetics and pharmacodynamics in the elderly. Exp Gerontol. 2003;38:843-853.

44. Gisclon LG, Riffitts JM, Sica DA, et al. The pharmacokinetics of topiramate in subjects with renal impairment as compared to matched subjects with normal renal function. Pharm Res. 1993;10(Suppl):S397.

45. Edwards I, Aronson J. Adverse drug reactions: definitions, diagnosis, and management. The Lancet. 2000;356:1255-1259.

46. Korean Topiramate Study Group. Low dose and slow titration of topiramate as adjunctive therapy in refractory partial epilepsies: a multicentre open clinical trial. Seizure. 2002;11:255-260.

47. Shorvon SD. Safety of topiramate: Adverse events and relationships to dosing. Epilepsia. 1996;37(Suppl 2):18-22.

48. Tatum WO, French JA, Faught E, et al. Postmarketing experience with topiramate and cognition. Epilepsia. 2001;42:1134-1140.

49. Bootsma HPR, Ricker L, Diepman L, et al. Long-term effects of levetiracetam and topiramate in clinical practice: A head-to-head comparison. Seizure. 2008;17:19-26.

50. Vega D, Maalouf NM, Sakhaee K. Increased propensity for calcium phosphate kidney stones with topiramate use. Expert Opin Drug Saf. 2007;6:547-557.

51. Welch BJ, Graybeal D, Moe OW, et al. Biochemical and stone-risk profiles with topiramate treatment. Am J Kidney Dis. 2006;48: $555-563$.

52. Lamb EJ, Stevens PE, Nashef L. Topiramate increases biochemical risk of nephrolithiasis. Ann Clin Biochem. 2004;41:166-169.

53. Adelman JFF, Lainez M, Shi Y, et al. Analysis of safety and tolerability data obtained from over 1500 patients receiveing topiramate for migraine prevention in controlled trials. Pain Med. 2008;9:175-185.

54. Thambi L, Kapcala LP, Chambers W, et al. Topiramate-associated secondary angle-closure glaucoma: a case series. Arch Ophthalmol. 2002;120:1108.

55. Blumenthal DT. Acute myopia and angle-closure glaucoma induced by topiramate. Neurology. 2004;63:762; author reply 762 .

56. Boentert M, Aretz H, Ludemann P. Acute myopia and angle-closure glaucoma induced by topiramate. Neurology. 2003;61:1306.

57. Kalinin V. Suicidality and antiepileptic drugs. Drug Saf. 2007;30: 123-142.

58. Mula M, Sander JW. Negative effects of antiepileptic drugs on mood in patients with epilepsy. Drug Saf. 2007;30:555-567. 
59. US Food and Drug Administration, Center for Drug Evaluation and Research. Information for Healthcare Professionals Suicidality and Antiepileptic Drugs, http://www.fda.gov/cder/drug/infopage/ antiepileptics/default.htm. Accessed Jan 31, 2008.

60. Nickel C, Lahmann C, Tritt K, et al. Topiramate in treatment of depressive and anger symptoms in female depressive patients: A randomized, double-blind, placebo-controlled study. J Affect Disord. 2005;87:243-252.

61. Mula M, Trimble MR, Lhatoo SD, et al. Topiramate and psychiatric adverse events in patients with epilepsy. Epilepsia. 2003;44:659-663.

62. Besag F. Behavioral effects of the new anticonvulsants. Drug Saf. 2001;24:513-536.

63. Han JH, Zimmerman EE, Cutler N, Schnelle J, et al. Delirium in older Emergency Department Patients: recognition, risk factors and psychomotor subtypes. Acad Emerg Med. 2009;16:1-8.

64. Tuma R, DeAngelis LM. Altered mental status in patients with cancer Arch Neurol. 2000;57:1727-1731.

65. Laurila JV, Laakkonen ML, Laurila JV, Strandberg ET, Reijo TS. Predisposing and precipitating factors for delirium in a frail geriatric population. J Psychosom Res. 2008;65:249-254.

66. Gaudreau JD, Gagnon P, Roy MA, Harel F, Tremblay A. Association between psychoactive medications and delirium in hospitalized patients: a critical review. Psychosomatics. 2005;46:302-316

67. Motamedi G, Meador K. Epilepsy and cognition. Epilepsy Behav. 2003;4:S25-S38.

68. Fratiglioni L, Wang H, Ericsson K. Influence of social network on occurrence of dementia: a community-based longitudinal study. Lancet. 2000;355:1315-1319.

69. Roe CM, Mintun MA, D’Angelo G, et al. Alzheimer disease and cognitive reserve. Arch Neurol. 2008;65:1467-1471.

70. Hall DB, Derby D, LeValley A, et al. Education delays accelerated decline on a memory test in persons who develop dementia. Neurology. 2009;69:1657-1664.

71. Jokeit H, Ebner A. Long term effects of refractory temporal lobe epilepsy on cognitive abilities: a cross sectional study. J Neurol Neurosurg Psychiatry. 1999;67:44-50.

72. Mills KC, Drazkowski JF, Hammer AE, Caldwell PT, Kustra RP, Blum DE. Relative influences of adjunctive topiramate and adjunctive lamotrigine on scanning and the effective field of view. Epilepsy Res 2006;78:140-146.

73. Salinsky MC, Storzbach D, Spencer DC, Oken BS, Landry T, Dodrill CB. Effects of topiramate and gabapentin on cognitive abilities in healthy volunteers. Neurology. 2005;64:792-798.

74. Kim SY, Lee HW, Jung DK, et al. Cognitive effects of low-dose topiramate compared with oxcarbazepine in epilepsy patients. J Clin Neurol. 2006;2:126-133.

75. Fritz N, Glogau S, Hoffmann J, Rademacher M, Elger CE, Helmstaedter C. Efficacy and cognitive side effects of tiagabine and topiramate in patients with epilepsy. Epilepsy Behav. 2005;6:373-381.

76. Kockelmann E, Elger C, Helmstaedter. Cognitive profile of topiramate as compared with lamotrigine in epilepsy patients on antiepileptic drug polytherapy: relationships to blood serum levels. Epilepsy Behav. 2004;5:716-721

77. Lee HW, Jung DK, Suh CK, Kwon SH, Park SP. Cognitive effects of low-dose topiramate mono-therapy in epilepsy patients: a 1-year followup. Epilepsy Behav. 2006:736-741.

Clinical Interventions in Aging

\section{Publish your work in this journal}

Clinical Interventions in Aging is an international, peer-reviewed journal focusing on evidence-based reports on the value or lack thereof of treatments intended to prevent or delay the onset of maladaptive correlates of aging in human beings. This journal is indexed on PubMed Central, MedLine, the American Chemical Society's 'Chemical Abstracts Ser-
78. Gordon AM, Logan BK. Topiramate-positive death-investigation and impaired-driving cases in Washington State. J Analytical Tox. 2006;30:599-602.

79. Kockelmann E, Elger CE, Helmstaedter C. Significant improvement in frontal lobe associated neuropsychological functions after withdrawal of topiramate in epilepsy patients. Epilepsy Res. 2003;54:171-178.

80. Werz MA, Schoenberg MR, Meador KJ, Loring DW, Ray PG, Gupta RK, et al. Subjective preference for lamotrigine or topiramate in healthy volunteers: relationship to cognitive and behavioral functioning. Epilepsy Behav. 2006;8:181-191.

81. Ghaemi SN, Manwani SG, Katzow JJ, Ko JY, Goodwin FK. Topiramate treatment of bipolar spectrum disorders: a retrospective chart review. Ann Clin Psychiatry. 2001;13:185-189.

82. Meador KJ, Loring DW, Vahle VJ, et al. Cognitive and behavioral effects of lamotrigine and topiramate in healthy volunteers. Neurology. 2005;64:2108-2114.

83. Fife TD, Sirven J. Antiepileptic drugs and their impact on balance. Aging Health. 2005;1:147-155.

84. Patsalsos PN, Berry DJ, Bourgeois BF, et al. Antiepileptic drugs - best practice guidelines for therapeutic drug monitoring: A position paper by the subcommission on therapeutic drug monitoring, ILADR Commission on Therapeutic Strategies. Epilepsia. 2008;49:1239-1276.

85. Garnett WR. Optimizing antiepileptic drug therapy in the elderly. Ann Pharmacother. 2005;39:1852-1860.

86. Arroyo S, Kramer G. Treating epilepsy in the elderly. Drug Saf. 2001;24:991-1015.

87. Aldenkamp AP, Baker G, Mulder OG, et al. A multicenter, randomized clinical study to evaluate the effect on cognitive function of topiramate compared with valproate as add-on therapy to carbamazepine in patients with partial-onset seizures. Epilepsia. 2000;41:1167-1178.

88. Mecarelli O, Piacenti A, Pulitano P, et al. Clinical and electroencephalographic effects of topiramate in patients with epilepsy and healthy volunteers. Clin Neuropharmacol. 2001;24:284-289.

89. Groselj J, Guerrini R, Van Oene J, et al. Experience with topiramate monotherapy in elderly patients with recent-onset epilepsy. Acta Neurol Scand. 2005;112:144-150.

90. Guerrrini R, Carpay J, Groselj J, et al. Topiramate monotherapy as broad-spectrum antiepileptic drug in a naturalistic clinical setting Seizure. 2005;14:371-380.

91. Runge U, Schauble B, Rettig K, et al. Topiramate-First line monotherapy in elderly patients with epilepsy. [abstract only full paper in German] Aktktuelle Neurol. 2007;34:272-275.

92. Ramsay RE, Uthman B, Pryor FM, et al. Topiramate in older patient with partial-onset seizures: A pilot double-blind, dose-comparison study. Epilepsia. 2008;49:1180-1185.

93. Martin RC, Griffith HR, Faught E, et al. Cognitive functioning in community dwelling older adults with chronic epilepsy. Epilepsia. 2005;46:298-303.

94. Griffith HR, Martin RC, Bambara JK, et al. Older adults with epilepsy demonstrate cognitive impairment compared with patients with amnestic mild cognitive impairment. Epilepsy Behav. 2006;8:161-168.

95. Meador KJ, Loring DW, Hulihan JF, et al. Differential cognitive and behavioral effects of topiramate and valproate. Neurology. 2003;60:1483-1488.

96. Blum D, Meador K, Biton V, et al. Cognitive effects of lamotrigine compared with topiramate in patients with epilepsy. Neurology. 2006;67:400-406

\section{Dovepress}

vice' (CAS), Scopus and the Elsevier Bibliographic databases. The manuscript management system is completely online and includes a very quick and fair peer-review system, which is all easy to use. Visit http://www.dovepress.com/testimonials.php to read real quotes from published authors. 